\title{
SISTEM PAKAR UNTUK MENGIDENTIFIKASI PENYAKIT MATA DENGAN METODE CERTAINTY FACTOR
}

\author{
Eka Putra', Yessy Asri ${ }^{2}$, Budi Prayitno ${ }^{3}$, dan Andi Dahroni ${ }^{4}$ \\ ${ }^{1,2,3,4}$ Teknik Informatika, Sekolah Tinggi Teknik PLN \\ E-mail: eka@sttpln.ac.id
}

\begin{abstract}
Eye disease today is no longer a rare disease suffered by humans. Many symptoms encountered makes people become confused if the types of eye diseases from which they suffer. Type of eye disease that often affects people of Indonesia according to the Ministry of Health is conjunctivitis, Pterygium, Cataract and Glaucoma. It's no secret if in a meeting with the ophthalmologist will cost not less. Expert systems are computer-based systems that use knowledge, facts and reasoning techniques in solving problems that normally can only be solved by an expert in the field. Forward chaining inference engine used in this study to chronicling the symptoms are inconclusive, then the certainty factor method so that we can determine what percentage of the disease in the suffering of patients through the results of the count in the method. Application web-based expert system created to provide information to people with eye disease illness is entered in accordance with the symptoms.
\end{abstract}

Keywords: Expert System, Forward Chaining, Certainty Factor, Web, Eye Disease

\begin{abstract}
ABSTRAK
Penyakit mata saat ini bukan lagi penyakit langka yang diderita manusia. Banyak gejala yang dijumpai membuat orang menjadi bingung jika jenis penyakit mata yang mereka derita. Jenis penyakit mata yang sering menyerang orang Indonesia menurut Departemen Kesehatan adalah konjungtivitis, Pterygium, Cataract dan Glaucoma. Bukan rahasia lagi jika dalam pertemuan dengan dokter mata biayanya tidak sedikit. Sistem pakar adalah sistem berbasis komputer yang menggunakan pengetahuan, fakta, dan teknik penalaran dalam memecahkan masalah yang biasanya hanya bisa diselesaikan oleh seorang ahli di bidangnya. Forward chaining inference engine yang digunakan dalam penelitian ini untuk mencatat gejala tidak dapat disimpulkan, maka metode faktor kepastian sehingga kita dapat menentukan berapa persentase penyakit dalam penderitaan pasien melalui hasil perhitungan dalam metode. Aplikasi sistem pakar berbasis web dibuat untuk memberikan informasi kepada penderita penyakit mata yang dimasukkan sesuai dengan gejalanya.
\end{abstract}

Kata kunci : Sistem Pakar, Forward Chaining, Certainty Factor, web, Penyakit Mata 


\section{PENDAHULUAN}

Mata merupakan salah satu dari panca indra manusia yang mempunyai fungsi untuk melihat. Dengan mata melihat, menusia dapat menikmati keindahan alam dan berinteraksi dengan lingkungan sekitar dengan baik. Pentingnya fungsi mata ini bagi kehidupan maka sudah seharusnya mendapatkan perlakuan khusus dalam penanganannya. Penyakit mata saat ini bukan lagi menjadi penyakit yang langka diderita oleh manusia. Banyaknya gejala-gejala yang ditemui membuat penderita menjadi bingung apakah jenis dari penyakit mata yang mereka derita. Dan juga bukan rahasia lagi jika dalam sekali pertemuan dengan dokter spesialis mata akan memakan biaya yang tidak sedikit. Dengan adanya masalah ini maka dapat disimpulkan bahwa nantinya penderita penyakit mata tidak akan dapat mengetahui penyakit mata jenis apa yang dideritanya.

Ditinjau dari permasalahan diatas, maka dirancanglah sebuah sistem pakar yang berguna untuk menggantikan kepakaran seseorang yang ahli dalam bidang penyakit mata atau biasa kita kenal dengan spesialis mata. Dengan cara melakukan pengumpulan fakta-fakta yang sebenarnya, dan dengan di bantu mesin inferensi forward chaining untuk merunutkan gejala-gejala yang memberikan kesimpulan, kemudian metode certainty factor agar kita dapat mengetahui berapa persen penyakit yang di derita penderita melalui hasil hitungan dalam metode tersebut. Dengan menimbang mahalnya biaya konsultasi kepada spesialis mata, maka adanya sistem ini diharapkan penderita mampu mengetahui jenis penyakit mata yang dialami tanpa konsultasi kepada spesialis mata terlebih dahulu.

\section{METODOLOGI PENELITIAN}

\subsection{Analisis Permasalahan}

Identifikasi masalah harus dilakukan untuk mengetahui permasalahan yang sedang dihadapi yang mana nantinya akan dijadikan objek penelitian. Tahap ini sangat penting karena proses analisa yang kurang akurat akan menyebabkan hasil dari pengembangan suatu perangkat lunak yang mana kita buat saat ini Sistem Pakar akan tidak sesuai dengan yang diharapkan. Jadi proses ini harus benar-benar sesuai dengan keinginan pengguna agar hasil pengembangan perangkat lunak tersebut akan memuaskan dan bermanfaat.

Berdasarkan permasalahan yang telah dirumuskan pada bab sebelumnya, maka dapat ditentukan beberapa pendekatan untuk menyelesaikan permasalahan tersebut. Pendekatanpendekatan tersebut antara lain :

1. Memahami, mengetahui dan mengidentifikasi jenis-jenis penyakit mata dengan melakukan wawancara dengan pakar yang bersangkutan (Spesialis mata) dan mencari bahan menunjang lainnya melalui webstite resmi Menkes.

2. Merancang Sistem Pakar yang dapat mengidentifikasi jenis penyakit mata apa yang di derita pada seseorang berdasarkan ciri-ciri yang dialami oleh pengguna sistem sekaligus memberikan solusi dari penyakit yang diderita, sehingga dapat membantu pengguna sistem dalam memperbaiki sikap dan perilakunya.

\subsection{Arsitektur Sistem Pakar}

Pada perancangan sistem, terdapat lima komponen sistem pakar yang digunakan antara lain: 


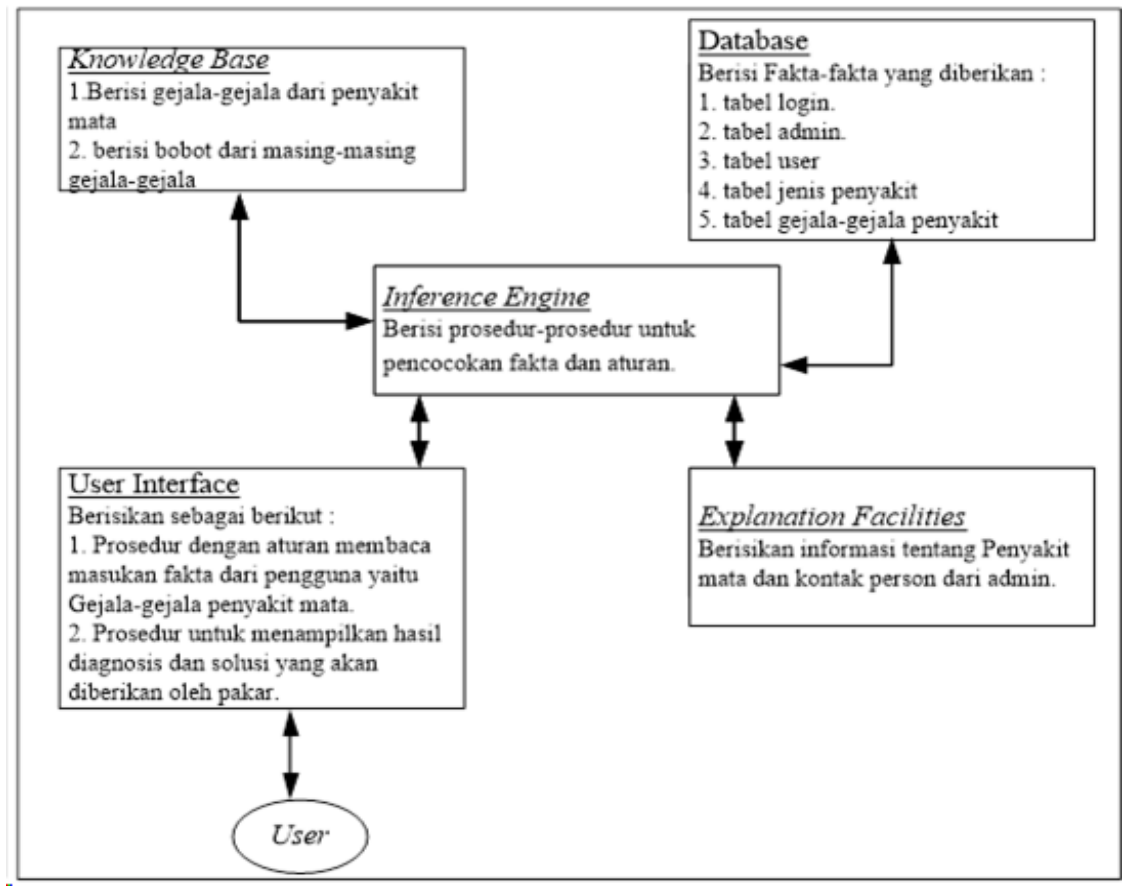

Gambar 1 Desain Arsitektur Sistem Pakar

Pada arsitektur sistem pakar gambar 1 dijelaskan keterhubungan antar komponen-komponen, yang mana inference engine sebagai pusat dari komponen tersebut. Selain itu ada juga komponen Knowledge Base, Database, User Interface, dan Explanation Facilities yang masing-masing komponen mempunyai elemen pendukung masing yang ditentukan oleh user dan pakar

\subsubsection{Jenis-Jenis Penyakit Mata}

Pada tabel 1 dibawah ini dijelaskan 4 nama dari jenis penyakit yang akan diteliti berdasarkan data yang telah diperoleh dari pakar. Dapat terlihat juga pengkodean dari jenis penyakit yang diteliti, yang mana pengkodeannya diinisialisasikan sendiri oleh peneliti.

Tabel 1. Jenis-Jenis Penyakit Mata

\begin{tabular}{|c|l|c|}
\hline No & Nama Penyakit & Kode Penyakit \\
\hline 1 & Konjungtivitis & P01 \\
\hline 2 & Pterygium & P02 \\
\hline 3 & Katarak & P03 \\
\hline 4 & Glaukoma & P04 \\
\hline
\end{tabular}

\subsubsection{Gejala-Gejala Penyakit Mata}

Pada tabel 2 tersebut dapat terlihat apa-apa saja gejala penyakit mata yang mungkin dirasakan oleh penderita, dan beberapa gejala tersebut didapatkan melalui pengumpulan data dengan wawancara oleh pakar. 
Tabel 2. Gejala-Gejala Penyakit Mata

\begin{tabular}{|c|c|c|}
\hline No & Nama Gejala & Kode Gejala \\
\hline 1 & Rasa mengganjal & G01 \\
\hline 2 & Mata terasa gatal dan berair & G02 \\
\hline 3 & Mata berwarna merah. & G03 \\
\hline 4 & Seret / Mata mengeluarkan kotoran & G04 \\
\hline 5 & $\begin{array}{l}\text { Faktor lingkungan sekitar ada yang menderita } \\
\text { penyakit yang sama }\end{array}$ & G05 \\
\hline 6 & $\begin{array}{l}\text { Mata berlemak / tampak jaringan lemak menutupi } \\
\text { permukaan mata }\end{array}$ & G06 \\
\hline 7 & Gatal atau perih pada mata. & G07 \\
\hline 8 & Pandangan samar/kabur. & G08 \\
\hline 9 & $\begin{array}{l}\text { Bekerja dibawah cahaya matahari / bekerja } \\
\text { dilingkungan berdebu }\end{array}$ & G09 \\
\hline 10 & $\begin{array}{l}\text { Penglihatan menurun secara perlahan seperti tertutup } \\
\text { asap/kabut }\end{array}$ & G10 \\
\hline
\end{tabular}

\subsection{Mekanisme Inferensi}

Sistem Pakar mengidentifikasi penyakit mata ini menggunakan mesin inferensi forward chining atau runut maju, dimana apabila if rule di dalam knowladge base terpenuhi maka rule tersebut akan diproses. Inference engine berfungsi menganalisa data dan kemudian akan menarik kesimpulan berdasarkan aturan yang ada.

Pada Sistem Pakar ini user diharuskan untuk menjawab pertanyaan sesuai dengan gejala yang dirasakan, dimana setiap jawaban memiliki bobot masing-masing, bobot tersebut akan disimpan di database, kemudian semua rule yang terpenuhi akan dihitung sehingga akan menghasilkan fakta baru dan mendapatkan kesimpulan.

\subsection{Analisa Proses}

Terdapat beberapa rule yang harus dihubungkan atau dipasangkan oleh peneliti dengan didampingi oleh pakar, terlihat ada tabel 3 dimana keterhubungan rule-rule tersebut dapat menentukan seberapa besar tingkat kepastian jenis penyakit mata yang dirasakan oleh penderita. 
Tabel 3. Aturan Kaidah (Rule) Berdasarkan Nilai CF

\begin{tabular}{|c|c|c|c|}
\hline No & IF & THEN & $\begin{array}{l}\text { NILAI } \\
\text { CF }\end{array}$ \\
\hline 1 & $\begin{array}{l}\text { IF G001 AND G002 AND G003 AND G004 } \\
\text { AND G005 } \\
\text { IF Rasa mengganjal AND Mata terasa gatal dan } \\
\text { berair AND Mata berwarna merah AND Seret / } \\
\text { Mata mengeluarkan kotoran AND Faktor } \\
\text { lingkungan sekitar ada yang menderita penyakit } \\
\text { yang sama }\end{array}$ & $\begin{array}{c}\mathrm{P} 01 \\
\text { Konjungtivitis }\end{array}$ & $\mathrm{CF}=0.90$ \\
\hline 2 & $\begin{array}{l}\text { IF G001 AND G002 AND G003 AND G004 } \\
\text { IF Rasa mengganjal AND Mata terasa gatal dan } \\
\text { berair AND Mata berwarna merah AND Seret / } \\
\text { Mata mengeluarkan kotoran }\end{array}$ & $\begin{array}{c}\text { P01 } \\
\text { Konjungtivitis }\end{array}$ & $\mathrm{CF}=0.75$ \\
\hline 3 & $\begin{array}{l}\text { IF G002 AND G003 AND G004 } \\
\text { IF Mata terasa gatal dan berair AND Mata } \\
\text { berwarna merah AND Seret / Mata } \\
\text { mengeluarkan kotoran }\end{array}$ & $\begin{array}{c}\mathrm{P} 01 \\
\text { Konjungtivitis }\end{array}$ & $\mathrm{CF}=0.60$ \\
\hline 4 & $\begin{array}{l}\text { IF G003 AND G004 AND G005 } \\
\text { IF Mata berwarna merah AND Seret / Mata } \\
\text { mengeluarkan kotoran AND Faktor lingkungan } \\
\text { sekitar ada yang menderita penyakit yang sama }\end{array}$ & $\begin{array}{c}\mathrm{P} 01 \\
\text { Konjungtivitis }\end{array}$ & $\mathrm{CF}=0.50$ \\
\hline
\end{tabular}

\subsubsection{Nilai Certainty Factor Dari Fakta Gejala Penyakit Mata}

Pada metode Certainty Factor ini diharuskan membuat apa-apa saja kemungkinan dari jawaban penderita penyakit mata, dan setiap kemungkinan tersebut diberikan nilai kemungkinan dengan arahan pakar. Pada tabel 4 di terlihat apa saja kemungkinan yang akan di ambil beserta dengan nilai bobotnya.

Tabel 4. Tabel Tingkat Keyakinan

\begin{tabular}{|c|c|}
\hline Certainty Term & CF \\
\hline Tidak Tahu & 0.2 \\
\hline Mungkin & 0.4 \\
\hline Kemungkinan Besar & 0.6 \\
\hline Hampir Pasti & 0.8 \\
\hline Pasti & 1.0 \\
\hline
\end{tabular}

Setelah rule - rule diketahui maka langkah selanjutnya adalah melakukan perhitungan pencarian nilai Hypothesis (fakta baru) dengan menggunakan rumus Certainty Faktor yaitu $C F$ ( $A$ $A N D B)=\operatorname{Min}(C F(A), C F(B)) * C F($ rule $)$. Adapun perhitungannya dapat dilihat sebagai berikut : 
Rule 1 : IF G01 (CF=1.00) AND G02 (CF=1.00) AND G03 (CF=0.20) AND G04 (CF=0.40) AND G005 $(\mathrm{CF}=0.20)$ THEN Penyakit=Konjungtivitis $=0.90$

$\mathrm{CF} 1=$ Konjungtivitis, $\mathrm{G} 01 \cap \mathrm{G} 02 \cap \mathrm{G} 03 \cap \mathrm{G} 04 \cap \mathrm{G} 05$

Min $(1.00 ; 1.00 ; 0.20 ; 0.40 ; 0.20) * 0.90$

$=0.18$

Fakta baru : Konjungtivitis

Rule 2 : IF G01 (CF=1.00) AND G02 (CF=1.00) AND G03 (CF=0.20) AND G04 (CF=0.40) THEN Penyakit=Konjungtivitis $=0.75$

CF2 = Konjungtivitis, G01 $\cap$ G02 $\cap$ G03 $\cap$ G04

Min $(1.00 ; 1.00 ; 0.20 ; 0.40) * 0.75$

$=0.15$

Fakta Baru : Konjungtivitis

Hypothesis $\mathrm{CF}=0.15$

Rule 3 : IF $\mathrm{G} 02$ (CF=1.00) AND $\mathrm{G} 03 \quad(\mathrm{CF}=0.20)$ AND $\mathrm{G} 04 \quad(\mathrm{CF}=0.40)$ THEN

Penyakit=Konjungtivitis $=0.60$

$\mathrm{CF} 3=$ Konjungtivitis, $\mathrm{G} 02 \cap \mathrm{G} 03 \cap \mathrm{G} 04$

Min $(1.00 ; 0.20 ; 0.40) * 0.60$

$=0.12$

Fakta Baru : Konjungtivitis

Setelah perhitungan selesai dari setiap rule - rule yang terpilih, maka Tabel dibawah terdapat bobot setiap hypothesis, yang mana setiap bobot tersebut mepunyai masing-masing nilai (bobot) beserta kode dari penyakit sesuai yang telah peneliti terapkan.

Tabel 5. Fakta Baru

\begin{tabular}{|c|c|c|}
\hline Fakta Baru & Hypoyhesis & Nilai CF \\
\hline P01 & Hypothesis & $\mathrm{CF}=0.18$ \\
\hline $\mathrm{P} 01$ & Hypothesis & $\mathrm{CF}=0.15$ \\
\hline $\mathrm{P} 01$ & Hypothesis & $\mathrm{CF}=0.12$ \\
\hline $\mathrm{P} 01$ & Hypothesis & $\mathrm{CF}=0.10$ \\
\hline $\mathrm{P} 02$ & Hypothesis & $\mathrm{CF}=0.19$ \\
\hline $\mathrm{P} 02$ & Hypothesis & $\mathrm{CF}=0.16$ \\
\hline $\mathrm{P} 02$ & Hypothesis & $\mathrm{CF}=0.17$ \\
\hline $\mathrm{P} 02$ & Hypothesis & $\mathrm{CF}=0.15$ \\
\hline $\mathrm{P} 03$ & Hypothesis & $\mathrm{CF}=0.19$ \\
\hline $\mathrm{P} 03$ & Hypothesis & $\mathrm{CF}=0.15$ \\
\hline $\mathrm{P} 03$ & Hypothesis & $\mathrm{CF}=0.16$ \\
\hline $\mathrm{P} 03$ & Hypothesis & $\mathrm{CF}=0.16$ \\
\hline $\mathrm{P} 04$ & Hypothesis & $\mathrm{CF}=0.18$ \\
\hline $\mathrm{P} 04$ & Hypothesis & $\mathrm{CF}=0.18$ \\
\hline $\mathrm{P} 04$ & Hypothesis & $\mathrm{CF}=0.16$ \\
\hline $\mathrm{P} 04$ & Hypothesis & $\mathrm{CF}=0.15$ \\
\hline
\end{tabular}

Setelah rule - rule diketahui maka langkah selanjutnya adalah melakukan perhitungan pencarian nilai Hypothesis (fakta baru) dengan menggunakan rumus Certainty Faktor yaitu $C F$ ( $A$ $A N D B)=\operatorname{Min}(C F(A), C F(B)) * C F($ rule $)$. Adapun perhitungannya dapat dilihat sebagai berikut

Fakta Baru :

1. Konjungtivitis

a. $=\mathrm{CF} 1+\mathrm{CF} 2 *(1-\mathrm{CF} 1)$

$$
\begin{aligned}
& =0.18+0.15 *(1-0.18) \\
& =0.2706
\end{aligned}
$$




$$
\begin{aligned}
\text { b. } & =0.2706+\mathrm{CF} 3 *(1-0.2706) \\
& =0.2706+0.12 *(1-0.2706) \\
& =0.2849 \\
\text { c. } & =0.2849+\mathrm{CF} 4 *(1-0.2849) \\
& =0.2849+0.10 *(1-0.2849) \\
& =0.2752
\end{aligned}
$$

Hasil kombinasi $* 100 \%=27.52 \%$

2. Pterygium

$$
\begin{aligned}
& =\mathrm{CF} 5+\mathrm{CF} 6 *(1-\mathrm{CF} 5) \\
& =0.19+0.16 *(1-0.19) \\
& =0.2835 \\
\mathrm{~b} . & =0.2835+\mathrm{CF} 7 *(1-0.2835) \\
& =0.2835+0.17 *(1-0.2835) \\
& =0.3249 \\
\mathrm{c} . & =0.3249+\mathrm{CF} 8 *(1-0.3249) \\
& =0.3249+0.15 *(1-0.3249) \\
& =0.3206
\end{aligned}
$$

Hasil kombinasi $* 100 \%=32.06 \%$

3. Katarak

$$
\begin{aligned}
\text { a. } & =\text { CF9 }+ \text { CF10 } *(1-C F 9) \\
& =0.19+0.15 *(1-0.19) \\
& =0.2754 \\
\text { b. } & =0.2754+\mathrm{CF} 11 *(1-0.2754) \\
& =0.2754+0.16 *(1-0.2754) \\
& =0.3154 \\
\text { c. } & =0.3154+\text { CF12*(1-0.3154) } \\
& =0.3154+0.16 *(1-0.3154) \\
& =0.3254
\end{aligned}
$$

Hasil kombinasi $* 100 \%=32.54 \%$

\section{HASIL DAN PEMBAHASAN}

Pada tahap ini dilakukan langkah-langkah pengoperasian Sistem Pakar untuk mendiagnosa penyakit mata pada seseorang.. Adapun tampilan program Sistem Pakar yang telah dirancang :

\subsection{Menu Login Admin}

Pada halaman index terdapat menu pilihan login yang akan memberikan akses kepada admin untuk memasukkan hak akses berupa email admin dan juga password. Admin pada sistem ini diberi hak untuk melakukan input dari sistem diagnose penyakit mata ini.

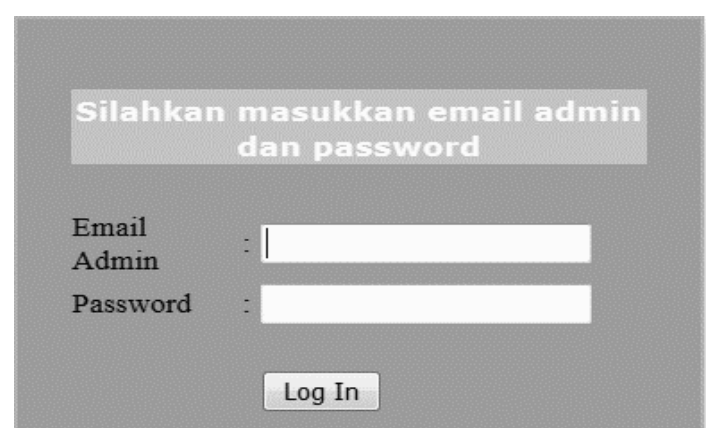

Gambar 2. Form Login Admin 


\subsection{Menu Pertanyaan}

Pada halaman pertanyaan ini admin memasukkan serangkaian pertanyaan yang berkaitan dengan gejala penyakit yang diderita oleh user. Setiap pertanyaan yang diinputkan oleh user harus berkaitan dengan ID gejala yang telah admin inputkan sebelumnya.

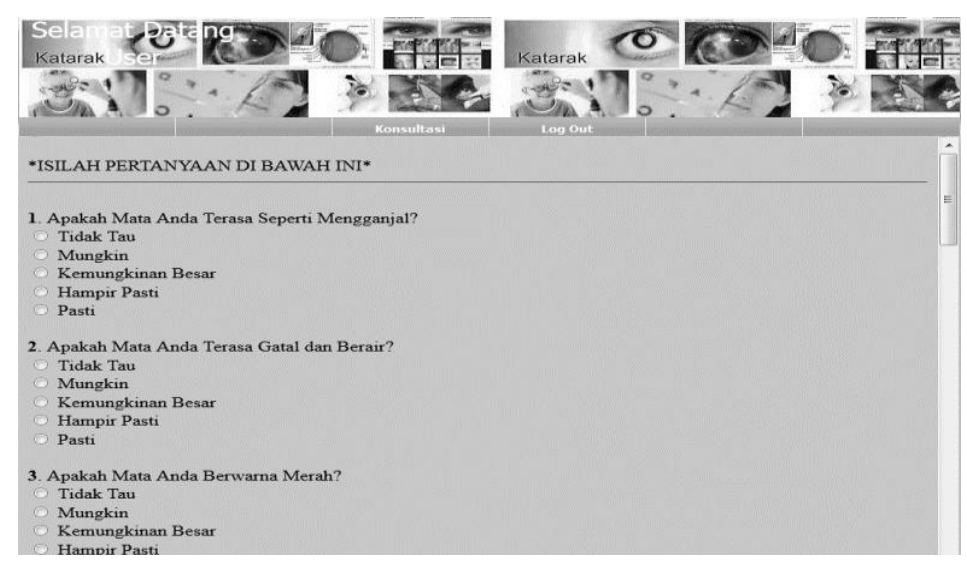

Gambar 3. Menu Pilihan Bagian Gejala-Gejala yang Dirasakan

a. Setelah melakukan konsultasi berdasarkan gejala yang dirasakan maka akan keluar hasil dari gejala-gejala yang dipilih beserta bobot masing-masing gejala.

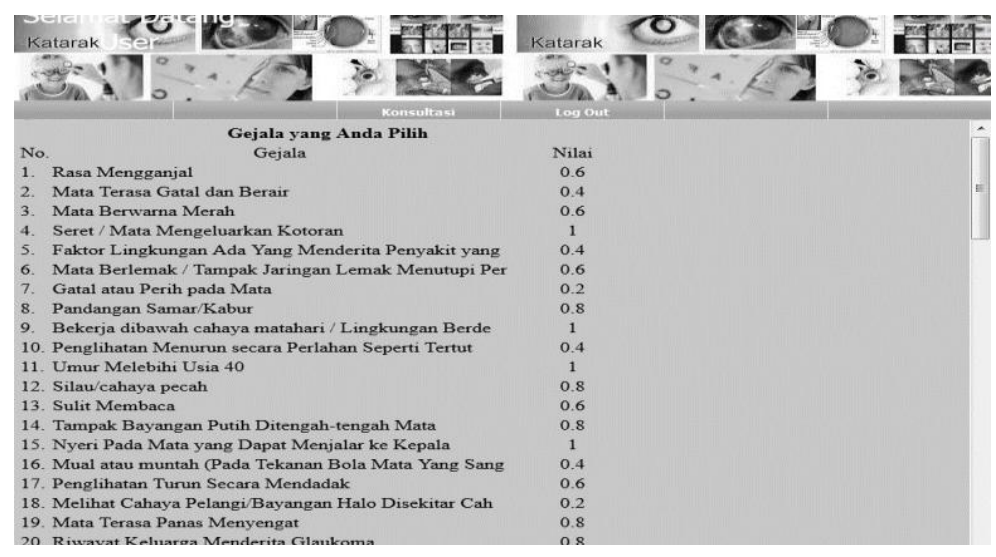

Gambar 4. Form Hasil Gejala Yang Dipilih

b. Jika terdapat rule-rule yang sama, maka sistem akan melakukan penggabungan rule.

\begin{tabular}{|c|c|c|c|}
\hline \multicolumn{4}{|c|}{ Jika terdapat rule yang samaa, maka rule tersebut digabungkan } \\
\hline \multicolumn{4}{|c|}{ Penggabungan rule } \\
\hline No & Penyakit & Penggabungan & hasil \\
\hline 1 & Konjungtivitis & $\begin{array}{l}(0.36+0.3) *(1-0.36)(0.552+0.24) *(1-0.552) \\
(0.65952+0.2)^{*}(1-0.65952)\end{array}$ & 0.727616 \\
\hline 2 & Pterygium & $\begin{array}{l}(0.19+0.16) *(1-0.19) \\
(0.2835+0.17) *(1-0.2835)\end{array}$ & 0.32061154547744 \\
\hline & & $(0.32493275+0.15) *(1-0.32493275)$ & \\
\hline 3 & Katarak & $\begin{array}{l}(0.38+0.3)^{*}(1-0.38) \\
(0.4216+0.48)^{*}(1-0.4216)(0.52148544+0.32)^{*}\end{array}$ & 0.40266303506801 \\
\hline & & $(1-0.52148544)$ & \\
\hline 4 & Glaukoma & $\begin{array}{l}(0.18+0.18)^{*}(1-0.18) \\
(0.2952+0.16)^{*}(1-0.2952)(0.32082496+0.3)^{*} \\
(1-0.32082496)\end{array}$ & 0.421648817041 \\
\hline
\end{tabular}

Gambar 5. Form Hasil Konsultasi Berupa Penggabungan Rule 
c. Setelah dihitung dari penggabungan rule-rule, maka akan diperoleh suatu kesimpulan penyakit melalui persentase paling tinggi, kemudian sistem juga memberikan solusi berupa penanganan tergantung penyakit apa yang diderita.

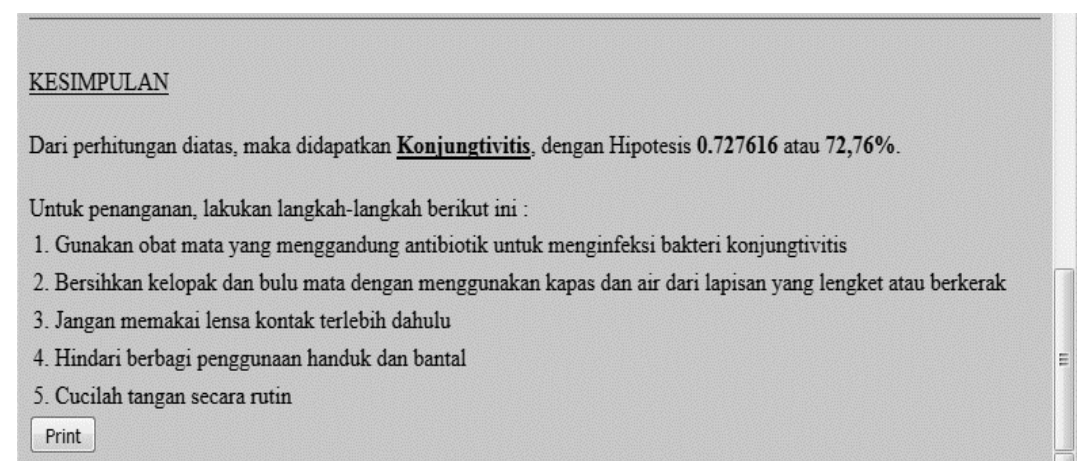

Gambar 6. Form Hasil Konsultasi Berupa Kesimpulan dan Solusi.

\section{KESIMPULAN DAN SARAN}

Sistem Pakar untuk mendiagnosa penyakit mata ini bertujuan untuk mengetahui gejala awal dari penyakit mata yang membuat masyarakat dapat melakukan antisipasi awal terhadap jenis penyakit yang diderita. Aplikasi Sistem Pakar ini dapat dikembangkan lagi cakupannya, sehingga topik yang dibahas tidak terbatas pada 4 jenis penyakit mata saja, tetapi diharapkan juga bisa untuk beberapa jenis penyakit mata lainnya.

\section{UCAPAN TERIMAKASIH}

Penulis mengucapkan terima kasih kepada Instansi/perusahaan/lembaga yang telah memberi dukungan yang membantu pelaksanaan penelitian dan atau penulisan artikel.

\section{DAFTAR PUSTAKA}

Gatot Fitriyanto (2016). Mendeteksi Hama Tanaman Buah Mangga Dengan Metode Certainty Factor. Elektro Universitas Informatika.

Indri Wulandari (2015). Perancangan Sistem Pakar Diagnosis Kerusakan Televisi Berwarna. Sekolah Tinggi Teknologi Garut.

Ihsan Yuliandri (2014). Diagnosa Gangguan Gizi Menggunakan Metode Certainty Factor. Teknik Informatika, UIN SUSKA Riau. ISSN : 2407-0939

Jusak (2013). Penerapan Metode Certainty Factor. Jurnal Sistem Informasi Bisnis 03 (2012).

Liyan Febrianti. Sistem Pakar Penanganan Penyakit Balita Dengan Metode Certainty Factor. Informatika Universitas Tanjungpura.

Muhammad Kurniawan. (2016). Mendeteksi Hama Tanaman Buah Mangga Dengan Metode Certainty Factor. STMIK Amikom Yogyakarta. ISSN : 2302-3805

Muhammad Arhami (2004). Konsep Dasar Sistem Pakar. Penerbit : Andi, Yogyakarta.

Mukhlis Ramadhan (2011). Sistem Pakar Dalam Mengidentifikasi Penyakit Kanker Pada Anak Sejak Dini Dan Cara Penanggulangannya. STMIK Triguna Dharma.

Nur Anjas Sari (2013). Sistem Pakar Mendiagnosa Penyakit demam Berdarah Menggunakan Metode Certainty factor. STMIK Budidarma Medan. ISSN : 2301-9425.

Reski Mai Chandra (2015). Sistem Pakar Penentuan Jenis Plastik Berdasarkan Sifat Plastik Terhadap Makanan Yang Akan Dikemas Menggunakan Metode Certainty Factor. Teknik Informatika UIN Sultan Syarif Kasim Riau. ISSN : 2460-738X.

Sri Hartati (2008). Kecerdasan Buatan. Penerbit : Andi Offset. Yogyakarta

Yugianus (2012). Penerapan Model Certainty Factor Untuk Mendeteksi Gejala Kanker Mulut Rahim. Sistem Informasi, Universitas Stikubank. 